\title{
Benefit Analysis of Environmental Protection Investment Based on Reciprocity Theory
}

\author{
Chenyuan Zhao, Tiantian Xiang, Huan Peng* \\ School of Economics and Finance, Chongqing University of Technology, Chongqing, China \\ Email: *68875894@qq.com
}

How to cite this paper: Zhao, C.Y., Xiang, T.T. and Peng, H. (2018) Benefit Analysis of Environmental Protection Investment Based on Reciprocity Theory. Theoretical Economics Letters, 8, 3395-3410. https://doi.org/10.4236/tel.2018.815208

Received: October 19, 2018

Accepted: November 26, 2018

Published: November 29, 2018

Copyright ( $) 2018$ by authors and Scientific Research Publishing Inc. This work is licensed under the Creative Commons Attribution International License (CC BY 4.0).

http://creativecommons.org/licenses/by/4.0/

(c) (i) Open Access

\begin{abstract}
This paper abandons the "rational man" hypothesis in traditional economics and utilizes the existing "reciprocal" principal-agent model (Pu Y. J, 2007) to analyze the benefits of environmental protection inputs. The results of the study show that if humans increase their environmental investment on the basis of rational input is set to $\eta$, naturally, the increase in revenue under the assumption of "reciprocity" is $r$, when $\eta>2 r$, the environmental investment made by humans under irrational assumptions can bring Higher income level than "rational people". Thus, the enlightenment of government behavior is: first, the government should fully recognize the "reciprocal" characteristics of the natural environment when formulating environmental protection policies; second, the government should further increase investment on the basis of rational input, when the increased investment meets the aforementioned conditions, the purpose of increasing human income can be achieved.
\end{abstract}

\section{Keywords}

Environmental Protection, Green Finance, Reciprocity, Principal-Agent Model

\section{Introduction}

The harmonious development of human society and the natural environment has always been an important issue in the process of social and economic development. In the process of development of human society, once the pollution and damage caused to the natural environment exceeds the limit of environmental tolerance that exceeds the bearer threshold of environment, not only the social and economic development is unsustainable, but also the human society has to pay a heavy cost. Therefore, it is necessary to invest funds for environmental protection in economic development. 
However, people have long recognized the importance of environmental protection investment. With the continuous development of the social economy, the population has increased greatly and the demand for resources has become more and more huge, especially the environmental and ecological pollution caused by the development of modern industry is getting worse. People gradually realized that natural resources are not inexhaustible and even began to become scarce resources that restrict human social and economic development. Therefore, environmental resources have become an important part of social productivity and their protection behavior should be involved in the distribution of national income. This part of national income allocated to environmental protection is environmental protection investment [1]. However, within a certain period of time, national income is certain. If the investment for environmental protection is increased, it will inevitably reduce other input, so the investment in environmental protection must be limited. Since environmental protection investment is limited, how to maximize the investment efficiency of environmental funds and how to make human society get the most benefit in the harmonious and sustainable development with nature, which become a very important issue affecting economic law exhibitions, what is more, it is a very important aspect of building a harmonious society.

This paper discusses this question from a special perspective, and it can provide a new way of thinking for the benefit of green investment. The structure of this paper is as follows: Part 2 is a review of relevant literature, which provides theoretical basis for the research; Part 3 is an analysis of the "prisoner's dilemma" of green investment; Part 4 is a principal-agent model of environmental protection investment under the condition of "rational person"; Part 5 is a principal-agent model of environmental protection investment under the theory of reciprocity; Part 6 is the conclusion and enlightenment.

\section{Literature Overview}

The relationship between man and nature is interdependent and indivisible. Nature is the material basis and premise of human existence and man is the product of the long-term development of nature. This is the harmony between man and nature [2]. Therefore, the relationship between man and nature should be mutually beneficial, which requires human beings to pay more attention to the protection of the environment while developing the economy. How much environmental protection should be invested and how to improve the efficiency of environmental protection investment has become an important issue in economic and social life.

Panayotou [3], after research in 30 countries, proved that environmental protection policies and inputs can reduce environmental degradation at low income levels and accelerate environmental improvement at high income levels, which is the environmental Kuznets curve. After that, Hettige and other people [4] used 12 countries' enterprise-level industrial wastewater discharge data for quantitative analysis and found that strict environmental protection policies and inputs 
are the main reasons for the decline of industrial wastewater discharge as income increases. In addition, some scholars in China have also carried out a series of studies using the Kuznets curve, for example, Wu Y.P and other people [5] empirically analyzed the background data with the Kuznets curve and concluded that Beijing reached the inflection point of the environmental Kuznets curve earlier than developed countries, which is mainly attributed to Beijing's strict and effective environmental protection policies and inputs; Xia Y.J and others [6] innovatively used method that is described the Kuznets curve using a cubic equation to conduct an empirical study on Lanzhou. Consequently, due to the implementation of certain environmental policies and inputs, not only has it maintained rapid economic growth, but also the environmental quality of the city has been significantly improved. Zhang H.F and others [7] used the Kuznets curve to empirically analyze the data in Shandong, indicating that the EKC inflection point can be changed through environmental policies and inputs, thereby achieving a win-win situation for environmental protection and economic development.

Other scholars have discussed the relationship between environmental protection investment and production efficiency. There are three main hypotheses: "constraint hypothesis", "porter hypothesis" and "uncertainty hypothesis". The "constraint hypothesis" believes that if the corresponding capital is invested to reduce pollution, which will internalize the negative externalities of the enterprise, what is more, increasing the cost burden of the enterprise and affecting the production efficiency of the enterprise. Gray's [8] research on the US manufacturing sector in the 1970s found that EPA regulation is part of the reason for the decline in productivity in the manufacturing sector. Jaffe [9] and others also found that environmental investment will lead to "crowding out effect", which will affect the production efficiency of the manufacturing industry; The "Porter Hypothesis" believes that through the "innovation compensation" and "first mover advantage", there may be a win-win situation for environmental and business productivity [10] [11], After Berman and Bui [12] studied the smelting industry in Los Angeles, they found that pollution control investment increased production efficiency, thus verifying the "Porter Hypothesis"; The "uncertainty hypothesis" considers that there are uncertainties in the factors affecting the relationship between environmental regulation and productivity, the choices for implementing environmental regulations in practice are also different, which leads to uncertainty in the impact of environmental regulation on firm productivity [13] [14], Brännlund [15] studied the data of the Swedish manufacturing sector and found that the relationship between environmental regulation and productivity growth was not significant.

In addition, some scholars' research on the benefits of environmental protection investment is based on the input-output model. For example, Leontief [16] first explored quantitative research on environmental issues under the framework of input-output analysis. Then, scholars such as Kneese [17] also tried to study environmental issues under the framework of input and output. Moreover, 
some scholars in China have used data envelopment analysis (DEA) to conduct qualitative research on the efficiency of environmental protection investment in some areas of China. For example, Yang C.M [18] applied DEA method to study the data of 30 provinces and municipalities in China and made a qualitative comparison of environmental protection investment efficiency in different regions. Yan W and Tang D.S [19] used the C2R model of DEA to conduct an empirical analysis of China's environmental protection input efficiency.

These studies are based on the classical hypothesis of complete rationality in traditional economics. The "rational person" assumes that people are all "rational people" who pursue self-interest, the purpose and motivation of all parties are to maximize the self-interest, which invisibly strengthens the contradictions and conflicts in social economic relations to a certain extent. Obviously, it is contrary to the connotation of environmental protection and cannot provide a reasonable explanation for the harmonious development of man and nature. In actual social life, the parties involved in behavioral choices do not have the conditions for complete information and the behavioral decisions made by people are not completely rational, they also are influenced by human factors such as personal feelings. Herbert Simon [20] thinks that the hypothesis of "rational man" utility maximizing behavior is conditional on complete rationality, but the uncertainty and complexity of the environment and the limited ability of human cognition, the judgment ability of economic individuals will be limited by both psychological and physiological, which result in the behavior of economic individuals is bounded rationality rather than complete rationality and Standard of decision is to seek satisfactory decision rather than the most favorable decision. The decision criterion is to seek satisfactory decision rather than the most favorable decision. Similarly, it is especially true when studying and analyzing the relationship between man and nature. In the past, the natural environment was regarded as a "rational person" to participate in the game for analysis. However, in reality, is it really completely rational? In fact, everything in nature is not rigidly run in accordance with people's imagination and design, which determines that nature cannot be described by the assumption of "rational people."

If the hypothesis of "rational people" is not conducive to the study and interpretation of the emergence of some cooperative behaviors in reality, what should be explained? From a biological point of view, the earliest explanation is that cooperation is conducive to the evolution of the group, so the biological individual will consider the interests of the group that is the theory of "group selection" [21]. Hamilton [22] introduced the theory of "kind selection" in the 1960s. The so-called "selection" in these two theories is from the perspective of biological evolution. It is believed that biological individuals not only consider their own genetic interests, but also consider the genetic interests of the groups. However, these theories still have great limitations, whether they are based on "egoism" or "altruism", they cannot explain the "free rider" behavior that exists within the group.

With the deepening of relevant research, behavioral economics and its reci- 
procity theory can break this limitation and explain it to some extent. Behavioral economics is an interdisciplinary subject that uses psychological principles and experimental methods to verify the basic behavioral assumptions of economics and uses behavioral games as its microscopic basis to study the laws of economic activity. Professor D. Kahneman of Princeton University and Professor A. Tversky of Stanford University [23] pointed out that people's behavior is not only driven by interests, but also by many psychological factors such as instinct, prejudice, discrimination and jealousy. Since these factors are neglected in traditional economics, there are many "abnormal" phenomena in the real society that cannot be explained by traditional economics. Behavioral economics believes that reciprocal preference is a tendency of conditional cooperation behavior and the key lies in the judgment of the other party's intention or belief. Thus, the theory of reciprocity was proposed by Trivers in 1971 [24] and the cooperation stems from mutual help between individuals. This is called direct reciprocity theory. I think: I will give you cooperation (help) this time. I hope that you can also cooperate with me next time. If you choose not to cooperate this time (not help), then next time I will also choose not to cooperate to retaliate. In the 1980s, Axelrod [25] conducted a computer experiment on the game strategy competition of "Prisoner's Dilemma". The experimental results show that the strategy of "reporting one report" is an evolutionary stability strategy, and its research results are considered to be a powerful verification of the "direct reciprocity" theory. Then, Alexander [26] further proposed the "indirect reciprocity" theory, that the cooperation between strangers is like a chain of cooperation, you helped me because he helped you, or because I will help him. In addition, Rabin [27] establishes a game theory model based on motivational fairness based on the game theory of mind. He introduces reciprocity preferences and believes that human behavior depends on the judgment of other people's motives: if the other party's behavior is considered, in good faith, then report to the other party in good faith; on the contrary, if the other party's behavior is considered malicious, then it will be malicious and hurt the other party. Even if helping and hurting the other party will harm your own interests, you will not hesitate. In short, it is "to repay the peaches, to return the teeth." $\mathrm{Pu} \mathrm{Y.} \mathrm{J} \mathrm{[28]} \mathrm{[29]} \mathrm{replaced} \mathrm{the} \mathrm{rational}$ man hypothesis with Rabin's motives, and modified the traditional principal-agent model to obtain a new contract theory based on the assumption of behavioral economics, so that the interests of both parties are Improved and achieved a win-win situation.

Similarly, when discussing the relationship between man and nature, we often call on people to "protect nature is to protect human beings", which fully demonstrates that the act of protecting nature is reciprocal to nature and mankind; building socialism in contemporary China. In a harmonious society, we also strongly advocate the construction of "harmony" between man and nature. The "harmony" here also emphasizes the reciprocity between man and nature. Therefore, the aforementioned theory of fair reciprocity can also be extended to the fair reciprocity and cooperation between man and nature. Saving nature and 
protecting the environment are essentially the reciprocal behavior between man and nature [30]. Therefore, when studying the relationship between man and nature, according to Rabin's theory, people and nature can be regarded as the reciprocal behavioral subject of "returning to the fore and returning to the teeth": if human beings are friendly to nature, then naturally It will be equally friendly to human beings. Human beings can continue to acquire resources and benefits from nature, which can make human society sustainable. On the other hand, if human beings are not friendly to nature and endlessly demanding from nature without knowing protection, then naturally Retaliation against humans resulted in environmental pollution and various ecological deterioration events.

\section{The "Prisoner's Dilemma" in Environmental Protection Investment}

Since the reform and opening up more than 30 years ago, China's economy has been moving at a rapid pace. Although it has harvested fruitful results in economic and social development, it has also paid the price of environmental problems. Economic construction has been at the Primary location for many years and environmental protection has fallen to a secondary position, in exchange for the rapid growth of the economy at the expense of natural resource consumption and environmental damage. Environmental problems such as smog and water pollution continue to remind us that this development is not the best way. If people and nature are regarded as both sides of the game, the choice of this behavior is in the "prisoner's dilemma."

In recent years, people have gradually recognized the importance of environmental protection and are also increasing their efforts and funding to manage and improve the natural environment. However, there are still many unreasonable behaviors in the development. The governance and investment of environmental protection often start to take action after some major environmental events have taken place.

We can explain this by creating a simple game model. Under the assumption of "rational man", since both human beings and nature are rational, if humans invest in environmental protection, they will be transformed into corresponding cost pressures, which will affect human economic benefits. when environmental problems exceeds the natural bearing limit, nature will retaliate against human beings through major environmental events, which can accelerate the recovery of nature itself, but will cause significant economic losses to human society. According to this, the following game matrix can be formed:

Thus human and natural behavioral choices will constitute the income matrix shown in Table 1 . The variables A, B, C, D, E, F, G, and $\mathrm{H}$ can be explained as follows in terms of quantity:

1) The relationship of human income in four cases. First of all, in the case of nature does not retaliate against the human society, it is clear that when humans do not invest in environmental protection, they have greater economic benefits than when they invest in environmental protection. Even if the living environment 
Table 1. The game behavior between man and nature at the precondition of hypothesis of rational man.

\begin{tabular}{ccc}
\hline & & \\
Numanity & No retaliation & retaliation \\
\hline investment & $(\mathrm{A}, \mathrm{B})$ & $(\mathrm{C}, \mathrm{D})$ \\
No investment & $(\mathrm{E}, \mathrm{F})$ & $(\mathrm{G}, \mathrm{H})$ \\
\hline
\end{tabular}

has been improved because of human input, nature has not retaliated against human beings. Therefore, human beings' feelings about environmental crises are not obvious and the investment in the environment has not brought corresponding benefits to have more feelings, so $\mathrm{A}<\mathrm{E}$; Secondly, in the case of nature choose to retaliate against human society, it is obviously that humans choose to invest less than economic loss when they choose not to invest, so $\mathrm{C}<\mathrm{G}$; Because the damage caused by natural retaliation is often very large, it is much more invested than humans in environmental protection, so $G<A$. In summary, "not investing" is a dominant strategy of human beings, the magnitude relationship of the benefits is $\mathrm{C}<\mathrm{G}<\mathrm{A}<\mathrm{E}$.

2) The relationship of natural income in four cases. First of all, In the case of humans choose to invest, the nature chooses retaliation for greater gains, because on the one hand the natural environment has benefited from human input, on the other hand the recovery has been completed through retaliation, so $\mathrm{B}<\mathrm{D}$, secondly, in the case of humans choose not to invest, the benefits of natural environment choice retaliation are also greater, so $\mathrm{F}<\mathrm{H}$, for nature, revenue is the same by retaliation against humans to complete environmental recovery, or through human input management to complete environmental recovery, that is to say $\mathrm{B}=\mathrm{H}$. All in all, "retaliation" for human beings is a dominant strategy of nature, the magnitude relationship of the benefits is $\mathrm{F}<\mathrm{H}$ $=\mathrm{B}<\mathrm{D}$.

Based on the above analysis, "not investing" is a dominant strategy of human beings. "Retaliation" is also a dominant strategy of natural. Therefore, (no investment, retaliation) is a Nash equilibrium in this case, $(G, H)$ is the benefits of all parties under the Nash equilibrium conditions. This equilibrium can explain in the real economic life that while developing the economy, it ignores the protection of the environment until it invites nature to retaliate against humans through major natural events. Under the assumption of rational people, it is easy to fall into a "prisoner's dilemma", that is, human beings have no incentive to invest in environmental protection, and naturally they will retaliate against human beings while human beings continue to deplete natural resources.

In fact, there is a better choice in this game model, which is (investment, no retaliation). This is because, when choosing (investing, not retaliation), the human benefit is the income $\mathrm{G}$ when $\mathrm{A}$ is greater than the choice (no investment, retaliation), and naturally the income in both cases is equal, i.e. $\mathrm{B}=\mathrm{H}$, then choose The total return A + B in the case of (investment, no retaliation) is significantly 
greater than the gain $\mathrm{G}+\mathrm{H}$ at the time of selection (no investment, retaliation). The concrete manifestation in reality is that while developing the economy, we must also pay attention to the protection of the natural environment, and control the consumption and destruction of nature within the range that the natural environment can bear, and then make people and nature develop harmoniously. However, people often wake up after experiencing natural violent revenge, only to know that they must protect the environment and make huge environmental protection investment. "First pollution and governance" is the situation in the model (investment, retaliation). The basic situation facing our country is this. In addition, (no investment, no retaliation) this situation is impossible.

\section{The Principal-Agent Model of Environmental Protection Investment under the Assumption of "Rational Person"}

\subsection{The Applicability of Principal-Agent Model}

The central problem of the principal-agent model is to solve the moral problems that arise due to information asymmetry. The model is a representative and generalized principal-agent model, which is widely used in the study of principal-agent relationships at home and abroad. In the model, the agent selects the level of effort to maximize its deterministic equivalent net income based on the constraints of incentive compatibility, and ensures that its deterministic equivalent net income is not less than its minimum net retained income. Under these two constraints, the principal seeks to maximize the incentives for his desired utility [31].

In essence, we can regard it as a game between human beings and nature. Human beings rely on nature to make gains, whether nature will retaliate against humans, and when and how to retaliate against human beings. It is said that the information is asymmetrical, or that human beings get the information at a high price, because once the natural retaliation against humans will cause irreversible losses. Therefore, we try to use the Holmstrom-Migrom principal-agent model [31] to conduct a specific study on this issue. Under this model, it is assumed that human beings are principals and naturally agents. On the one hand, they can be explained by the principal-agent relationship: 1) The key feature is that the interests of the principal are closely related to the behavior of the agent. Human beings obtain profits through natural demand. If human consumption of natural resources and environmental damage do not exceed the environmental carrying capacity, humans can continue to obtain from nature for profit; if human consumption of natural resources and environmental damage exceeds The carrying capacity of the environment will naturally retaliate against human beings and cause human economic losses. 2) The entrusting party cannot directly control the agent, and can only indirectly affect the agent's behavior through remuneration. Human beings cannot accurately predict the major environmental events caused by nature (such as earthquakes, tsunamis, sandstorms, typhoons, volcanic eruptions, etc.), and it is even more impossible to control 
nature. Humans can only reduce the occurrence of natural disasters by protecting the environment and degree. On the other hand, the principal assumptions of the principal-agent can be used to explain the conflict of interest between the principal and the agent: 1) Human beings exchange profits for the consumption of natural resources and the destruction of the environment. Naturally, they resort to retaliation against human beings through natural disasters and other means, causing great losses to the human economy. If humans want to protect nature, they have to give up some profits, so that there is conflict between humans and nature. 2) Information asymmetry between the principal and the agent. When human beings ask for resources from nature, they do not know when and where nature will retaliate against human beings. Although human beings know more or less about nature as technology advances, humans do not control the laws of nature. Still full of mystery, human beings are still in the stage of exploration, so the relationship between human and nature forms an information asymmetry. In summary, humans can be regarded as principals and naturally regarded as agents.

As mentioned in the previous section, the best way to develop the economy is to focus on the protection of the natural environment while controlling the economy, and to control the consumption and destruction of natural resources within the limits of the natural environment. However, when investing in the protection of the environment, how much is invested is efficient, and whether the best way of economic development can be achieved is the issue that we should focus on.

\subsection{Model Establishment}

Let $a$ be the contribution or sacrifice naturally made to meet the development needs of human beings. It is a one-dimensional variable; the total benefit of human beings obtained from nature is $\pi: \pi=\alpha+\theta$, where $\theta$ is the process by which humans obtain benefits from nature. Other uncertainties faced in the middle, and $\theta$ obeys a normal distribution with 0 as the mean and $\sigma^{2}$ as the variance, so expect $E(\pi)=a$ and variance $\operatorname{Var}(\pi)=\sigma^{2}$.

In general, we assume that humans are risk-neutral, and naturally risk-averse (because natural adventures will cause significant losses to humans), and the absolute risk aversion of humans and nature is constant, and both sides The optimal choice is linear [31].

Nature as an agent, its income function is: $s(\pi)=\alpha+\beta \pi, \alpha$ is the spontaneous contribution of human beings to environmental protection in life (such as people out of morality or compassion, to rescue wild animals; or consciously garbage Classification and recycling, etc.), $\beta$ is the share or proportion of human (government) that uses part of the total national economic income for environmental protection purposes.

Since human beings are risk-neutral as principals, given the natural (agent) income function $s(\pi)=\alpha+\beta \pi$, the human (client) utility function can be set 
to $v[\pi-s(\pi)]$, and the expected utility of human beings is:

$$
E v[\pi-s(\pi)]=v\{E[\pi-s(\pi)]\}=v\{E[-\alpha+(1-\beta) \pi]\}=v[-\alpha+(1-\beta) a]
$$

Since the first derivative of function $v[\pi-s(\pi)]$ is a constant, it is possible to assume that $w$ is the benefit of the human (client) after the environmental protection input, and there is $v(w)=w$, then the expected utility of the human (client) is equal to the expected return, that is $E v[\pi-s(\pi)]=-\alpha+(1-\beta) a$.

As the previous assumption, the absolute risk aversion of the natural (agent) is constant and is a constant, set to $\rho$, and then set $m$ as the actual income of the natural (agent), then the calculation formula according to the risk aversion degree is:

$$
\rho=-\frac{u^{\prime \prime}}{u^{\prime}}, \quad \rho>0
$$

So $\rho=-\frac{\mathrm{d} \ln u^{\prime}}{\mathrm{d} m}, \ln u^{\prime}=-\rho m+B$, where $B$ is an arbitrary constant.

Then there are $u^{\prime}=\mathrm{e}^{B} \mathrm{e}^{-\rho m}$, the solution gets $u=-\frac{\mathrm{e}^{B}}{\rho} \mathrm{e}^{-\rho m}+C$, where $B$ and $C$ are constants. For the sake of simplicity, we can set $B=\ln \rho$, and thus there are $\frac{\mathrm{e}^{B}}{\rho}=1$, so the whole formula becomes $u=-\mathrm{e}^{-\rho m}$.

According to the principal-agent model, we set $c(a)$ as the cost of the natural (agent) sacrifice to satisfy the needs of humans (principals) $a$ the cost of complete self-recovery, which is equivalent to the cost of money, and $c(a)=b a^{2} / 2$, where $b>0$ is the cost coefficient.

Therefore, the actual benefits of nature (agents) are:

$$
m=s(\pi)-c(a)=\alpha+\beta(a+\theta)-\frac{b a^{2}}{2}
$$

According to the definition of deterministic equivalent income: If $u(\chi)=E u(m)$, where $m$ is random income and $u(\chi)$ is the utility function of income, then $\chi$ is $m$ deterministic equivalent income. Therefore, for nature as an agent, there are: $-\mathrm{e}^{-\rho \chi}=\int-\mathrm{e}^{-\rho m} g(\theta) \mathrm{d} \theta$, of which $g(\theta)=A \mathrm{e}^{-\frac{\theta^{2}}{2 \sigma^{2}}}$ is a normal distribution density function of $\theta$, so there are:

$$
-\mathrm{e}^{-\rho \chi}=-\int \mathrm{e}^{-\rho\left[\alpha+\beta(a+\theta)-\frac{b a^{2}}{2}\right]} A \mathrm{e}^{-\frac{\theta^{2}}{2 \sigma^{2}}} \mathrm{~d} \theta
$$

After finishing, get:

$$
-\mathrm{e}^{-\rho \chi}=-\mathrm{e}^{-\rho\left(\alpha+\beta a-\frac{b a^{2}}{2}-\frac{\rho \beta^{2} \sigma^{2}}{2}\right)}
$$

So have: $\chi=\alpha+\beta a-\frac{b a^{2}}{2}-\frac{\rho \beta^{2} \sigma^{2}}{2}=E(m)-\frac{\rho \beta^{2} \sigma^{2}}{2}$, therefore, $\chi$ is a deterministic equivalent income of $m$.

Assume that the maximum environmental pollution and damage caused by human economic development, that is, the carrying threshold of the natural en- 
vironment is $n$, that is, the ultimate return of natural being is lower than this limit, it is necessary to conduct human revenge. So it satisfies the constraints:

$$
\chi=\alpha+\beta a-\frac{b a^{2}}{2}-\frac{\rho \beta^{2} \sigma^{2}}{2} \geq n
$$

Order $\frac{\partial \chi}{\partial a}=0$, calculate $a=\frac{\beta}{b}$.

Therefore, under rational conditions, the maximum benefit and input of humans (principals) should be the solution to the following problems:

$$
\begin{aligned}
& \max _{\alpha, \beta}[-\alpha+(1-\beta) a] \\
& \text { s.t. } \alpha+\beta a-\frac{b a^{2}}{2}-\frac{\rho \beta^{2} \sigma^{2}}{2} \geq n \\
& a=\frac{\beta}{b}
\end{aligned}
$$

In the principal-agent model, the constraint of the above problem is an equation, so the constraint is brought into the objective function, which can be calculated:

$$
\begin{gathered}
\alpha=n+\frac{1}{2}\left(\rho \sigma^{2}-\frac{1}{b}\right) \frac{1}{\left(1+b \rho \sigma^{2}\right)^{2}} \\
\beta=\frac{1}{1+b \rho \sigma^{2}}>0
\end{gathered}
$$

At this time, the expected benefits that human beings receive as principals are:

$$
E v=-n+\frac{1}{2 b\left(1+b \rho \sigma^{2}\right)}
$$

$\alpha$ As a human being's spontaneous contribution to environmental protection in life, its promotion relies on the vigorous publicity and education of government departments and public media; $\beta$ as a large-scale and purposeful environmental protection investment of government departments, it is environmental protection. The main part of the investment; and under the rational assumptions, the maximum benefit that humans can get is $E V$, which is certainly much greater than the gains that humans receive when they suffer losses due to natural retaliation.

\section{The Principal-Agent Model of Environmental Protection Investment under the Theory of Reciprocity}

Considering nature as a party to participate in the game, if the assumption of "rational man" is abandoned to transform the principal-agent model, then Rabin's reciprocity theory of "returning the money and repaying the teeth" is more suitable to explain the nature of nature. Nature can be described in this way: if human beings are friendly to nature and know how to be kind to nature when acquiring resources, then nature will also return to human beings, so that human society and economy will continue to develop; if human beings are not 
friendly to nature, they will be unrestrained in nature. Development and destruction, then it will also retaliate against humans. Therefore, we can try to introduce Rabin's reciprocity theory into the principal-agent model, and then analyze the investment and benefits of environmental protection.

If humans (principals) increase the investment of environmental protection funds on the basis of rational input, the total income of nature (agent) under the maximum contribution condition is higher than its minimum acceptable limit $n$, The increase of the input amount is $0 \leq r \leq \eta$; and naturally as an agent, its behavior is consistent with the previous reciprocity, so naturally it will make more contributions to human beings than under rational conditions to increase human income, and this increased contribution is $a^{*}$. Therefore, the natural deterministic benefit is $n+r$, and $n+r$ is less than the natural benefit of naturally increasing the contribution of human beings without increasing their contribution to environmental protection, that is $0 \leq r \leq \eta$.

Under the assumption of "rational people", people's spontaneous contribution to environmental protection in life is $\alpha_{0}$, even under the assumption of "reciprocity". Therefore:

$$
\begin{gathered}
\alpha_{0}+\eta+\beta\left(a+a^{*}\right)-\frac{1}{2} \rho \beta^{2} \sigma^{2}-\frac{b}{2}\left(a+a^{*}\right)^{2}=n+r \text { Solution: } \\
a^{*}=\frac{1}{b} \sqrt{2 b(\eta-r)+\left(1-b \rho \sigma^{2}\right)\left[\beta^{2}-\frac{1}{\left(1+b \rho \sigma^{2}\right)^{2}}\right]} \text { (tossing negative roots) }
\end{gathered}
$$

And because humans increase the proportion of the purpose of environmental protection investment on the basis of rational input, so $\beta$ is unchanged, and $\beta=\frac{1}{1+b \rho \sigma^{2}}$, so there are:

$$
a^{*}=\frac{1}{b} \sqrt{2 b(\eta-r)}
$$

Because of $0 \leq r \leq \eta$, we get $a^{*} \geq 0$, which means $a^{*}$ is a meaningful real solution. In the case that humans (principals) increase their input, $0 \leq r \leq \eta$ on the one hand shows that the contribution of nature to human beings is greater than that under rational conditions, and that nature as an agent has chosen to be smaller than its rational state. In return for human beings, the benefits of human beings must also increase, and the natural behavior must be "reciprocal".

Thus, under irrational conditions, the expected benefits of humans (clients) are:

$$
E v^{*}=-\alpha_{0}+(1-\beta)\left(a+a^{*}\right)-\eta=-\alpha_{0}+(1-\beta)\left[\frac{\beta}{b}+\frac{1}{b} \sqrt{2 b(\eta-r)}\right]-\eta
$$

Find $E v^{*}$ to $\eta$ partial derivatives and make them equal to 0 :

$$
\eta=r+\frac{b \rho^{2} \sigma^{4}}{2\left(1+b p \sigma^{2}\right)^{2}}
$$

Obviously, $r \leq \eta$. 


$$
E v^{*}=E v-r+\frac{b \rho^{2} \sigma^{4}}{2\left(1+b p \sigma^{2}\right)^{2}}
$$

among them, $E v=-n+\frac{1}{2 b\left(1+b p \sigma^{2}\right)}$ is the expected return of human beings under rational assumptions.

As can be seen from the calculation results of $E v^{*}$, There will be $E v^{*} \geq E v$ when $\frac{b \rho^{2} \sigma^{4}}{2\left(1+b \rho \sigma^{2}\right)^{2}} \geq r$. And because

$$
\eta=r+\frac{b \rho^{2} \sigma^{4}}{2\left(1+b \rho \sigma^{2}\right)^{2}}, \frac{b \rho^{2} \sigma^{4}}{2\left(1+b \rho \sigma^{2}\right)^{2}}=\eta-r
$$

so $\frac{b \rho^{2} \sigma^{4}}{2\left(1+b \rho \sigma^{2}\right)^{2}}>r$ can be rewritten as $\eta>2 r$, that is to say, when humans increase the environmental investment on the basis of rational input more than twice the amount of natural increase under the "reciprocity" hypothesis, human beings Under irrational conditions, the gains obtained under rational conditions are greater, and the actual returns are also higher than their carrying thresholds.

Using the principal-agent model based on the hypothesis of "rational man" to study the behavioral game between human and nature, the optimal strategy is to require the constraint to give the natural (agent) actual income exactly equal to the natural carrying threshold. Or the natural income of nature is at the edge of the carrying threshold, which is the inevitable choice of human (client) as a "rational person." That is to say, in the game, human beings as rational agents will inevitably give nature as little real income as possible while keeping nature (agents) from retaliation, because if you increase the actual income of nature, then increasing the cost of human beings is not conducive to gaining benefits. On the other hand, humans also believe that rational nature does not allow humans to gain more benefits by increasing profits.

However, after the improvement of the principal-agent model, it is proved that at $\eta>2 r$ time, the income of human and nature in the irrational state can be greater than the maximum benefit in the rational state, and then the total income of the system composed of man and nature. It is also greater than the total system revenue under rational conditions. This is a result of making people's investment in environmental protection more efficient, and mutual benefit and win-win between man and nature. In fact, this is a Pareto improvement of human and natural game behavior.

It is also foreseeable that in different natural environments or in different aspects of the natural environment, the natural reciprocity motivations are not the same (That is $r$, there are big and small), so humans can use the characteristics of natural irrationality. Carry out environmental protection investment. Pay attention to environmental protection inputs while obtaining resources from nature, For example, investment in environmental protection under the conditions put 
in more rational than $\eta=r+\frac{b \rho^{2} \sigma^{4}}{2\left(1+b \rho \sigma^{2}\right)^{2}}$, Thereby, human society and nature develop in harmony, and thus gain greater benefits, achieve sustainable use of natural resources and sustainable development of human society.

\section{Conclusions}

The existing analysis and research on environmental protection investment and benefit are generally carried out under the assumption of "rational person". According to the current behavioral economics and behavioral game theory, this paper expands the "rational person" hypothesis into the "reciprocity" hypothesis. The commission-agent model of environmental protection investment benefit analysis embodying "reciprocal" irrational behavior was constructed. Through the research and analysis of the model, the results show that the introduction of "reciprocity" makes it possible for humans to give more benefits than their carrying limit in the process of environmental protection input, it will increase the benefits of humans. When humans increase their environmental investment on the basis of rational input by more than twice the increase in the amount of income under the assumption of "reciprocity", humans and nature receive higher returns under the assumption of "reciprocity". The benefits obtained under the assumption of "rational people" will enable environmental protection inputs to have higher benefits and achieve sustainable economic development. The game result based on the "rational man" hypothesis is not a mutually beneficial win-win result, and the game result based on "reciprocity" shows that man and nature can achieve mutual benefit and win-win.

Therefore, the enlightenment on the behavior of environmental protection government is: First, the government should not regard the natural environment as the "rational" nature of pursuing profit maximization when formulating environmental protection policies, but should have a certain degree of "reciprocity". Naturally, it can be seen from the above $\eta>2 r$ condition that the greater the reciprocity of nature, the smaller the increase in environmental protection investment. Secondly, when the government invests in environmental protection, it only needs to increase the rational input. The amount of environmental protection input $\eta$ is greater than twice the natural increase $r$ in income under the assumption of "reciprocity", which can achieve the goal of further increase in environmental protection investment efficiency under the "rational" assumption.

In addition, for the convenience of research, in this paper, the maximum carrying capacity of the natural environment, that is, the carrying threshold of the natural environment, is set to a constant in the construction of the model. However, in practice, with the deepening of regional social and economic activities and the development of the regional environmental system itself, the regional environmental carrying capacity will change [31]. Therefore, how to study the benefits of environmental protection investment under the circumstances that 
the carrying capacity of the natural environment is constantly changing will be the research to be carried out in the future.

\section{Acknowledgements}

The authors thank the financial support of Humanity and Social Science Project 18SKSJ052 from the Chongqing Education Commission. (Project title: Regional competition and cooperation, economic development and sustainable growth in Chongqing.)

Also thanks for the financial support of the national social science fund of China 18XJY022 (Fund title: Study on the Feasible Ways to Develop Green Finance in the New Era).

\section{Conflicts of Interest}

The authors declare no conflicts of interest regarding the publication of this paper.

\section{References}

[1] Cai, N. and Lv, Y. (1997) Economic Analysis of Industrial Environmental Protection Investment. China Soft Science, 2, 116-120.

[2] Marx, E. (1974) The Complete Works of Marx and Engels (volume 25). People's Publishing House, Beijing.

[3] Panayotou, T. (1997) Demystifying the Environmental Kuznets Curve: Turning a Black Box into a Policy Tool. Environment and Development Economics, 2, 465-484. https://doi.org/10.1017/S1355770X97000259

[4] Hettige, H., Mani, M. and Wheeler, D. (2000) Industrial Pollution in Economic Development: Kuznets Revisited. Journal of Development Economics, 62, 445-476. https://doi.org/10.1016/S0304-3878(00)00092-4

[5] Wu, Y.P. and Dong, S.C. (2002) Evaluating Environmental Policy of Beijing. Urban Environment \& Urban Ecology, 15, 4-6.

[6] Xia, Y.J., Chen, X.P. and Li, N. (2006) Evaluating the Environment Policy of Valley Metropolis in Northwest China-A Case Study of Lanzhou. Journal of Lanzhou University (Natural Sciences), 42, 1-5.

[7] Zhang, H.F., Zhou, F., Yang, H. and Guo, Q. (2009) Regulation Performance of the Win-Win of Environmental Protection and Economic Development. Economic Research Journal, 3, 14-26.

[8] Gray, W.B. (1987) The Cost of Regulation: OSHA, EPA and the Productivity Slowdown. American Economic Review, 77, 998-1006.

[9] Jaffe, A.B., Peterson, S.R., Portney, P.R. and Stavins, R.N. (1995) Environmental Regulation and the Competitiveness of U S Manufacturing: What Does the Evidence Tell Us? Journal of Economics Literature, 33, 132-163.

[10] Porter, M.E. (1991) America’s Green Strategy. Scientific American, 264, 1-5.

[11] Porter, M.E and van der Linde, C. (1995) Toward a New Conception of the Environment: Competitiveness Relationship. Journal of Economic Perspectives, 9, 97-118. https://doi.org/10.1257/jep.9.4.97

[12] Berman, E. and Bui, L.T.M. (2001) Environmental Regulation and Productivity: 
Evidence from Oil Refineries. The Review of Economics and Statistics, 83, 498-510. https://doi.org/10.1162/00346530152480144

[13] Barbera, A.J. and McConnell, V.D. (1990) The Impact of Environmental Regulations on Industry Productivity: Direct and Indirect Effects. Journal of Environmental Economics and Management, 18, 50-65. https://doi.org/10.1016/0095-0696(90)90051-Y

[14] Wagner, M. (2004) The Porter Hypothesis Revisited: A Literature Review of Theoretical Models and Empirical Test. RePEcWPA, Sweden.

[15] Brännlund, R. (2008) Productivity and Environmental Regulations: A Long-run Analysis of the Swedish Industry. Working Paper, Sweden.

[16] Leontief, W. (1970) Environmental Repercussions and the Economic Structure: An Input-Output Approach. The Review of Economics and Statistics, 5, 262-271. https://doi.org/10.2307/1926294

[17] Kneese, A.V., et al. (1970) Economics and the Environment: A Materials Balance Approach. The Johns Hopkins Press, Baltimore, 1-120.

[18] Yang, C.M. (2007) Study on Efficiency of Environmental Protection Input Based DEA Model. Jinan University, Guangzhou.

[19] Yan, W. and Tang, D.S. (2007) Assessment on Relative Efficiency of Environmental Input in China Based on DEA Model. Productivity Research, No. 4, 21-23.

[20] Simon, H. (2007) Administrative Behavior. China Machine Press, Beijing, 60-76.

[21] Price, G.R. (1972) Extension of Covariance Selection Mathematics. Annals of Human Genetics, 35, 485-490. https://doi.org/10.1111/j.1469-1809.1957.tb01874.x

[22] Hamilton, W.D. (1963) The Evolution of Altruistic Behavior. The American Naturalist, 97, 354-356. https://doi.org/10.1086/497114

[23] Kahneman, D. and Tversky, A. (1974) Judgment under Uncertainty: Heuristics and Biases. Science, No. 4157, 1124-1131.

[24] Trivers, R.L. (1971) The Evolution of Reciprocal Altruism. The Quarterly Review of Biology, 46, 35-57. https://doi.org/10.1086/406755

[25] Axelrod, R. (1985) The Evolution of Cooperation. Basic Books, New York, 100-260.

[26] Alexander, R.D. (1987) The Biology of Moral Systems. Transaction Pub., New York, 150-320.

[27] Rabin, M. (1993) Incorporating Fairness into Game Theory and Economics. American Economic Review, 83, 1281-1302.

[28] Pu, Y.J. (2007) A Model Incorporating Fairness into Principal-Agent: A Contribution from Behavior Economics. Contemporary Finance \& Economics, No. 3, 5-11.

[29] Pu, Y.J. (2007) The Principal-Agent Model Based on Behavioral Economics Theory: A Substitute of Material Utility and Motivation. Economics, 7, 297-318.

[30] Pu, Y.J. (2012) Ideas, Theories and Models of Equity and Reciprocity. Journal of Chongqing Radio and TV University, 24, 3-10.

[31] Zhang, W.Y. (1996) Game Theory and Information Economics. Shanghai SDX Joint Publishing, Shanghai. 